This is the Accepted Author Manuscript of the following publication:

Boutin H, Pinborg L. TSPO imaging in stroke: from animal models to human subjects. Clin Transl Imaging. 2015;3(6):423-435.

The final publication is available at: http://link.springer.com/article/10.1007/s40336-015-0146-7 


\section{TSPO imaging in stroke: from animal models to human subjects}

2 Hervé Boutin ${ }^{1}$, Lars H. Pinborg*2

3 Short title: TSPO imaging in stroke

$4{ }^{1}$ Wolfson Molecular Imaging Centre, Faculty of Medical and Human Sciences, University of 5 Manchester, Manchester, M19 1GX, United Kingdom.

$6{ }^{2}$ Neurobiology Research Unit, Department of Neurology, Rigshospitalet, Copenhagen,

7 Denmark (email: lars.pinborg@nru.dk)

8 Address for correspondence: Neurobiology Research Unit, the Neuroscience Center,

9 Rigshospitalet, 9 Blegdamsvej, Copenhagen, DK-2100, Denmark

10 Telephone number: +4535456712

11 Fax number: +4535456713

12 Email: lars.pinborg@nru.dk

$13 *$ Corresponding author 


\section{Abstract}

Stroke is a major health problem in developed countries and neuroinflammation has

3 emerged over the last 2 decades as major contributor to the pathophysiological processes of brain damage following stroke. PET imaging of the translocator $18 \mathrm{kDa}$ protein (TSPO) provides a unique non-invasive point of access to neuroinflammatory processes and more specifically microglial and astrocytic reaction after stroke in both animal models and patients. Here we are reviewing both the experimental and clinical literature about in vivo TSPO PET and SPECT imaging in stroke. The studies in animal models of stroke reviewed here highlight a slightly faster time-course for TSPO expression in permanent vs. temporary stroke and a stronger activation in the infarct core in temporary stroke vs. a stronger activation in peri-infarct areas in permanent stroke. Altogether these findings suggest that areas where neuroinflammatory events occur post-stroke are at higher risk of secondary damage. The time-course of TSPO expression is slower in humans versus animal models of stroke. In human studies the TSPO expression in the peri-infarct areas peaks 3-4 weeks after stroke and increased TSPO expression is demonstrated for months after the stroke in remote areas both ipsilesional to pyramidal tracts damage and in the contralesional hemisphere. Further clinical studies are warranted to address the role of TSPO and neuroinflammation in functional recovery and reorganisation after stroke and the possible therapeutic implications. TSPO imaging appears to be a valid biomarker for demonstrating the dynamic process of neuroinflammation in stroke. But it is also clear that as the processes of microglial activation are increasingly complex, the need for new biomarkers and tracers targeting other aspect of glial reaction are needed to further investigate neuroinflammatory processes in patients. 
1

\section{Introduction}

After being identified and initially named peripheral benzodiazepine receptors $(\mathrm{PBR})[1,2]$ or peripheral benzodiazepine binding site (PBBS) and later renamed TSPO[3], the potential of PBR/TSPO as biomarkers of brain damage after stroke was rapidly identified[4,5] and taken forward in in vivo PET imaging[6] and exploited in subsequent studies. After being initially identified as general marker of brain damage, it quickly became clear that expression of TSPO was associated with glial reaction and/or macrophages infiltration[4,5,7]. Later on Stephenson et al. [8] demonstrated that activated microglial cells were the main source of parenchymal TSPO. Overall these studies paved the way to the use of TSPO as biomarker of neuroinflammation, and more specifically microglial activation and macrophages infiltration. In the early in vivo PET imaging studies, the tracer used for TSPO PET imaging was the $\left[{ }^{11} \mathrm{C}\right]$ labelled version of one of the ligand initially used for the characterisation of the PBR/TSPO: PK11195[9]. As detailed below, the first in vivo post-stroke PET studies performed in the early 1990 's were focusing on the characterisation of the time-course of TSPO expression to establish its potential use as biomarker of ischemic damage. In these early studies and until Shah et al.[10] showed that the R enantiomer of PK11195 had greater affinity for TSPO in 1994, a racemic of R/S-PK11195 was used. With the emergence, in the late 1990's, of neuroinflammation as a major contributor in stroke damage[11,12], TSPO PET imaging gained a renewed interest. Between the first study in a stroke model in baboons by Sette et al. [13] in 1993 and the next in vivo PET study in experimental stroke in 2007[14], clinical studies in stroke patients took place and are discussed in the clinical part of this review and several ex vivo experimental studies $[8,15-19]$ using $\left[{ }^{3} \mathrm{H}\right] \mathrm{PK} 11195$ were performed confirming the more rapid and transient time course of glial activation in rodents than in primates. With the emergence of preclinical PET scanner dedicated to small animals and the regained interest 
1 for neuroinflammation, TSPO imaging also saw a major effort my many groups to develop

2 new TSPO tracers with improved characteristics when compared to $\left[{ }^{11} \mathrm{C}\right]-(\mathrm{R})-\mathrm{PK} 11195$, namely

3 lower non-specific binding leading to an improved signal-to-noise ratio. Many of these

4 experimental studies used various models of excitotoxicity as a quick and easy way of inducing

5 microglial activation in animals to screen new TSPO tracers (for review see [20]). Following

6 the development of series of new tracers, those were then tested in models more relevant

7 from a clinical point-of-view than crude excitotoxic lesion, including stroke models; and from

8 the mid 2000's stroke models were then coupled with TSPO imaging in order to i) better

9 understand the time-course of microglial activation and ii) test new TSPO PET radiotracer in

10 a clinically relevant model.

\section{In vivo TSPO PET imaging in experimental stroke}

In order to select references for this review, the following search was performed in PubMed: (omega* OR TSPO OR PBR OR PK11195) AND (PET OR positron) AND (brain OR cereb*) AND (stroke OR ischem* OR ischaem*) AND (rat OR mouse OR mice OR animal* OR experimental OR pig OR gerbil OR rabbit OR guinea OR primate OR dog OR cat) AND (English[lang]). This search returned 53 references, of which 27 are reviewed in the sections below. Were excluded all references using other models than stroke lesions, purely in vitro work (binding or autoradiographic studies) or clinical work, the latter being reviewed in a dedicated paragraph of this manuscript.

\section{TSPO as biomarker of neuroinflammation in experimental stroke}

\section{Experimental models of stroke}

Various model of experimental stroke are widely used in stroke research inducing either focal or global ischemia in the brain. Only models of focal ischemia have been used in 
1 conjunction with TSPO PET imaging, therefore only those models are briefly discussed below,

2 for more details on the subject and pros and cons of each model, extensive reviews on the

3 subject are available[21-24]. Whether focal ischemia is obtained by occlusion of a major

4 vessel such as the middle cerebral artery (MCA) or injection of micro-emboli, these models

5 can grossly be categorised in transient and permanent which results in a different pattern of

6 brain lesion from a morphological and time-course point of views. Injection of micro-emboli

7 at the bifurcation between the MCA and the circle of Willis or electrocoagulation of the MCA

8 result in permanent stroke inducing brain damages which evolve faster and are primarily

9 hypoxic, rather than inflammatory, when compared with transient ischemia. In transient

10 ischemia (induced by temporary occlusion through the use of a thrombin clot or a filament,

11 by ligature of the MCA), the hypoxic early stages of the ischemia are followed by secondary

12 damages induced by oxidative stress and inflammatory components including gliosis and

13 infiltration of immune cells in the parenchyma. In the following paragraph we will review and

14 compare the results of experimental stroke studies using transient and permanent models of 15 stroke.

\section{Transient ischemia}

In a rather complex first in vivo PET study by Sette et al.[13], baboons were scanned 1 to 4 times at various time-points ( 1 to 91 days) after transient middle cerebral artery occlusion (MCAO) with ${ }^{15} \mathrm{O}$-labeled $\mathrm{CO}_{2}, \mathrm{O}_{2}$, and $\mathrm{CO}$ to map $\mathrm{CBF}$ and blood-volume-corrected $\mathrm{CMRO}_{2}$, respectively, and with $\left[{ }^{11} \mathrm{C}\right] \mathrm{PK} 11195$ for TSPO expression and $\left[{ }^{11} \mathrm{C}\right]$ flumazenil for central benzodiazepine receptor expression as marker of neuronal cell death. As each animal was not scanned at each time-point, the data points represent a trend over a population rather than a longitudinal follow-up of the TSPO expression; nevertheless these results suggest a gradual 
1 increase in TSPO expression in infarcted and peri-infarcted areas between day 10 and day 30,

2 before returning to baseline thereafter. Interestingly, this study showed significant increase

3 in $\left[{ }^{11} \mathrm{C}\right]$ PK11195 uptake together with decrease in $\left[{ }^{11} \mathrm{C}\right]$ flumazenil binding but importantly

4 neither of those tracer uptake were related to change in $\mathrm{CBF}$ or $\mathrm{CMRO}_{2}$, hence demonstrating

5 that $i$ ) these alterations were not just reflecting changes in perfusion and ii) were respectively

6 reflecting induction of a glial response and neuronal loss in the infarct but also in areas not

7 directly affected by the hypoperfusion. It is only much later, in the late 1990's, that new TSPO

8 PET imaging studies will take place due to the emergence of microPET system dedicated to

9 small animals. In such a study, Imaizumi et al.[14] measured $\left[{ }^{11} \mathrm{C}\right]$ PBR28 uptake following bolus or bolus-infusion protocols in rats 4 and 7 days post-MCAO (60min intra-luminal MCAO) and showed increased $\left[{ }^{11} \mathrm{C}\right]$ PBR28 specific binding in the peri-infarct and to less extent in the core of the infarct, a result confirmed by in vitro $\left[{ }^{3} \mathrm{H}\right] \mathrm{PK} 11195$ autoradiography. However, the study is underpowered ( $n=2$ for bolus injection and $n=1$ for bolus-infusion protocol) and it is unclear from the methods at which time-points each protocol was performed, hence no conclusion can be made whether there was significant increase in TSPO expression between day 4 and day 7 post-MCAO. Therefore this study provides little information about the timecourse of TSPO expression after stroke but demonstrates the feasibility of PET imaging in rodent after stroke. In a more comprehensive study, Rojas et al.[25] described more precisely the time course of TSPO expression following experimental stroke $(60 \mathrm{~min}$ intra-luminal MCAO) showing no significant increase in $\left[{ }^{11} \mathrm{C}\right]-(\mathrm{R})-\mathrm{PK} 11195$ uptake until 4 days post-MCAO with a further increase 7 days post-MCAO, results which were confirmed by $\left[{ }^{3} \mathrm{H}\right] \mathrm{PK} 11195$ autoradiography, TSPO PCR and immunohistochemistry analysis. In this study the authors also showed that CD11b (Ox42) (a cell surface protein expressed by activated microglia and infiltrated macrophages) positive cells were mostly responsible for TSPO expression although 
1 in the peri-infarct region some activated astrocytes also over-expressed TSPO. Interestingly,

2 the authors noticed that the expression by microglia/macrophages and astrocytes was

3 heterogeneous, in term of localisation and time-course. From day 4, TSPO expression was

4 found in amoeboid microglia/macrophages located in the core of the infarct and in the peri-

5 infarct region although these cells were less abundant in the peri-infarct region supporting

6 the observation of lower $\left[{ }^{11} \mathrm{C}\right]-(\mathrm{R})-\mathrm{PK} 11195$ uptake or TSPO immunostaining in this region. In

7 the peri-infarct region the predominant cell type is reactive astrocytes of which some were

8 found positive for TSPO immunostaining. Overall, these observations demonstrate a

9 differential expression of TSPO depending on the cells type and the phenotype and level of activation or of these cells. The relation between cell types, level of activation and overexpression of TSPO is still unclear, but it however seems to be associated with phagocytic activity (erythrophagocytosis in this case) which is consistent with the amoeboid phenotype of the microglia/macrophages found in the ischemic core. In two consecutive studies Martin et al. $[26,27]$ used one of the new TSPO tracer: $\left[{ }^{18} \mathrm{~F}\right] \mathrm{DPA}-714$ to thoroughly investigate TSPO expression after experimental transient ischemia in rats ( $2 \mathrm{~h}$ intra-luminal MCAO). These authors followed TSPO expression between 1 and 30 days post-MCAO and demonstrated that TSPO expression increased significantly from day 4 and peaked at day 11 post-MCAO and gradually decreased thereafter but remained significantly higher than baseline up to 21 days post-MCAO[28], results that were confirmed by autoradiography. Interestingly, they demonstrated by immunohistochemistry that between day 4 and day 11 , microglia/macrophages were the main cell populations responsible for TSPO over-expression and that thereafter the number of TSPO-positive decreased while the number of TSPOpositive astrocytes gradually increased. The expression of TSPO by microglial cells was already well established and later confirmed by Hughes et al. [29] showing a significant correlation 
1 between the localisation and amplitude of $\left[{ }^{11} \mathrm{C}\right]-(\mathrm{R})-\mathrm{PK} 11195$ uptake and Ox42 (CD11b)

2 immunostaining 14 days after $45 \mathrm{~min}$ distal MCAO. Similarly, the possible expression of TSPO

3 by astrocytes[28] was reported in fewer publication[25,7] but was later more specifically

4 confirmed by others[30]. In a more recent study using a new model of remote temporary

$5 \mathrm{MCAO}$ [31], Toth et al. [32] demonstrated using $\left[{ }^{11} \mathrm{C}\right] \mathrm{PBR} 28$ that TSPO expression peaked in

6 the infarct core slightly earlier (day 4 post-ischemia) in their model than the previous reports,

7 although there was no evidence of a significant difference in TSPO level between day 4 and 7

8 post-stroke, with again expression of TSPO in microglia (peak at day 4) and then slightly later

9 on in astrocytes (peak at day 7). Altogether these publications describe a common timecourse and pattern of microglial cell activation and TSPO expression (Figure 1). Despite the studies by Rojas et al.[25] and Toth et al.[32] indicating that TSPO expression is concomitant or precedes an increase in phagocytic activity, the precise function of TSPO in microglia and astrocytes and the reason for this shift in expression remain to be fully understood. This question of the relation between TSPO expression and function of glial cells has become quite essential if TSPO PET imaging is going to be used as read-out for therapeutic efficacy of drugs that modulate microglia activity or neuroinflammation in stroke and other neurodegenerative diseases. For example, Martin et al.[26] demonstrated that minocycline (an antibiotic which is able to reduce microglial proliferation) was able to decrease TSPO expression measured by ${ }^{18}$ F]DPA-714 PET but not infarct size. This finding is partly in contradiction with a more recent study[33] which showed no effect of minocycline on $\left[{ }^{11} \mathrm{C}\right]-(\mathrm{R})-\mathrm{PK} 11195$ uptake nor infarct size, although it must be noted that this study used a model of permanent stroke by microembolism rather than a temporary MCAO model[26]. These two studies suggest that the overall inhibition of microglial proliferation might not be the best strategy when compared to other approaches targeting specific cytokines[34-40], at least in the context of 
1 stroke. However, the study by Martin et al.[28], together with the clinical study by Dodel et

2 al.[41], still support the use of TSPO PET imaging as a valid biomarker of microglial 3 proliferation and/or activation for therapeutic read-out. The study of Wang et al.[42]

4 illustrates this point further as they used [ $\left.{ }^{18} \mathrm{~F}\right] \mathrm{DPA}-714$ PET imaging to assess the anti5 inflammatory effects of the drug AMD3100 (a specific antagonist of the chemokine receptor 64 (CXCR4)) following 60min of intraluminal MCAO in mice. Despite the challenges of microPET 7 imaging in mice, the authors confirmed in mice a similar time-course of TSPO expression observed in rats. However, one can note that the amplitude of the changes measured in mice are lower than those observed in rats (ipsi- to contralateral ratio $<2$ in mice and 4.6 in rats[43]), the explanation for this, outside possible difference between rat and mouse model, are likely to be the consequence of partial volume effect affecting more severely mouse than rat data quantification. Nevertheless, these authors were able to show a decrease in TSPO expression at 3 days post-stroke in the AMD3100-treated group. Overall, these studies using inflammatory modulators demonstrate that TSPO PET imaging is a suitable tool to monitor anti-inflammatory therapies.

\section{Permanent ischemia}

In a model of permanent stroke by microembolism (injection of macrospheres of 315$355 \mu \mathrm{m}$ in diameter in the internal carotid artery), Schroeter et al.[44] used a combination of $\left[{ }^{18} \mathrm{~F}\right]$ FDG uptake modelling and $\left[{ }^{11} \mathrm{C}\right]-(\mathrm{R})-\mathrm{PK} 11195$ imaging to determine three region of interest (ROI): infarct core (decreased cerebral blood flow (CBF) and metabolism), infarct margins (decreased CBF but unchanged metabolism) and peri-infarct (increased metabolism and increased $\left[{ }^{11} \mathrm{C}\right]-(\mathrm{R})-\mathrm{PK} 11195$ uptake). Whether the increased metabolism in the periinfarct zone was purely due to increased metabolic demand from neurons or a combination 
1 of neuronal activity and glial proliferation remains unclear, however together with the

2 presence of neuroinflammation it is likely to indicate an increased risk to secondary

3 inflammatory damage for the brain tissue in this area. Fukumoto et al.[45,46] further

4 investigated, in two multi-tracer studies, using $\left[{ }^{11} \mathrm{C}\right]-(\mathrm{R})-\mathrm{PK} 11195$ and $\left[{ }^{11} \mathrm{C}\right]$ flumazenil for

5 central benzodiazepine receptor (CBR) and $\left[{ }^{18} \mathrm{~F}\right] \mathrm{FDG}$ for glucose metabolism $[45]$ or $\left[{ }^{18} \mathrm{~F}\right] \mathrm{BMS}-$

6 747158-02 (Mitochondrial Complex-1 ligand)[46], the time-course and localisation of TSPO

7 expression after permanent stroke (photothrombotic model). These authors found that $\left[{ }^{11} \mathrm{C}\right]-$

8 (R)-PK11195 uptake matched in localisation the hypermetabolism detected in the peri-

9 infarcted area by $\left[{ }^{18} \mathrm{~F}\right] \mathrm{FDG}$, whereas a decrease in $\left[{ }^{18} \mathrm{~F}\right] \mathrm{flumazenil}[45]$ and $\left[{ }^{18} \mathrm{~F}\right] \mathrm{BMS}-747158$ -

02 [46] uptake could be detected in the infarct core. In term of time-course, they showed that TSPO expression was low 1 day post-stroke[46] and increases progressively to peak around day 7 post-ischemia and decrease thereafter (day 14)[45]. In another study, Walberer et al.[47] pushed further the time-course assessment of neuroinflammation and TSPO expression by imaging rats at 2, 7, 14, 21, 42 days and 7 months after photothrombotic stroke. They confirmed the known pattern of preferential expression of TSPO in the peri-infarcted region and lower in the infarct core increasing from day 2 up to day 7 , decreasing thereafter.

17 They however demonstrated that neuroinflammation as detected by $\left[{ }^{11} \mathrm{C}\right]-(\mathrm{R})-\mathrm{PK} 11195$ PET and ex vivo measurement, appeared at later time-point ( 7 months post-stroke) in the ventrolateral part of the thalamus, an area remote of the infarct and in which perfusion and $\left[{ }^{18} \mathrm{~F}\right]$ FDG uptake appeared normal. These findings are in agreement with ex vivo data reporting retrograde degeneration of thalamic nuclei several months after permanent stroke in rats[48,49]. In a follow-up study using the macrosphere model, the same group demonstrated overlap between over-expression of TSPO and infiltration of Ultrasmall SuperParamagnetic Iron Oxide (USPIO)-loaded macrophages (to image phagocytic activity) 
1 mostly in the infarct margins whereas the peri-infarct zone and sites of secondary injury

2 (ventrolateral thalamus) were only positive for $\left[{ }^{11} \mathrm{C}\right]-(\mathrm{R})$-PK11195 at day 7 post-stroke. By

3 following animals at 28 and 56 days post-stroke, their study suggest that areas positive for

4 USPIO-loaded macrophages alone or USPIO-loaded macrophages and [ $\left.{ }^{11} \mathrm{C}\right]-(\mathrm{R})-\mathrm{PK} 11195$ at 7

5 days post-stroke were not viable at later time-point whereas areas positive only for $\left[{ }^{11} \mathrm{C}\right]-(\mathrm{R})$ -

6 PK11195 remains viable.

Following the general consensus from all the studies described above, it is interesting

8 to note that the preferential localisation of the TSPO over-expression in the peri-infarct area

9 reported by Imaizumi et al.[14] after transient ischemia matches the results of the studies using permanent stroke rather than transient stroke. This suggests, in the absence of perfusion data in the study of Imaizumi et al.[14], that reperfusion might have been poor or inexistent leading to $i$ ) a different profile of microglial activation (i.e. higher in the rim of the infarct rather than the core) and ii) prevented tracer diffusion in the core of the infarct, hence explaining the higher uptake the peri-infarct area observed by Imaizumi et al.[14].

\section{Validation of new TSPO PET radiotracers in stroke models}

In other studies, stroke models were used not so much to investigate neuroinflammatory processes but to test or validate new TSPO radiotracers. As mention before, this field did regain much interest over the last decade due to the renewed interest for neuroinflammation in stroke and various neurodegenerative diseases and the availability of dedicated animal PET scanners. In such a study, Yui et al.[50] tested two new compounds, $\left[{ }^{18} \mathrm{~F}\right]-\mathrm{FEAC}$ and $\left[{ }^{18} \mathrm{~F}\right]-\mathrm{FEDAC}$, in rat post-MCAO. The authors showed that the uptake ratios 22 between ipsilateral and contralateral sides for $\left[{ }^{18} \mathrm{~F}\right]-\mathrm{FEAC}$ and $\left[{ }^{18} \mathrm{~F}\right]-\mathrm{FEDAC}$ were respectively 233.03 and 2.76 twenty minutes after injection, and the $B P_{N D}$ values were $1.70 \pm 0.19$ for $\left[{ }^{18} \mathrm{~F}\right]$ - 
1 FEAC and $1.37 \pm 0.06$ for $\left[{ }^{18} \mathrm{~F}\right]-F E D A C$. In 2 related studies, the same authors investigated

2 another compound, $\left[{ }^{11} \mathrm{C}\right] \mathrm{DAC}[51,52]$, and demonstrated the importance of using high specific

3 activity (SA) in small animals in order to get the best signal-to-noise ratio, as illustrated by the

4 differences in ipsi- to contralateral ratio ranging from $4.62 \pm 0.15$ for high $S A, 2.94 \pm 0.43$ for

5 middle SA, and $2.87 \pm 0.63$ for low SA. Although, in all these studies, the authors did not compare these 2 tracers with $\left[{ }^{11} \mathrm{C}\right]-(\mathrm{R})-\mathrm{PK} 11195$, the ipsi- to contralateral ratio obtained with

$7 \quad\left[{ }^{18} \mathrm{~F}\right]-\mathrm{FEAC}$ and $\left[{ }^{18} \mathrm{~F}\right]-\mathrm{FEDAC}$ are similar or even lower to those obtained with $\left[{ }^{11} \mathrm{C}\right]-(\mathrm{R})-\mathrm{PK} 11195$

8 in other studies, whereas those obtained with $\left[{ }^{11} \mathrm{C}\right] \mathrm{DAC}$ at high SA are better than those

9 typically obtained with $\left[{ }^{11} \mathrm{C}\right]-(\mathrm{R})-\mathrm{PK} 11195[25,53,54]$. It must be noted however than these studies[25,53,54], the SA of $\left[{ }^{11} \mathrm{C}\right]-(\mathrm{R})-\mathrm{PK} 11195$ was not as high as those used by Yui et al.[51,52] for $\left[{ }^{11} \mathrm{C}\right] \mathrm{DAC}$. In their studies, Yui et al.[51,52] also confirmed the preferential localisation of the highest TSPO tracer uptake after temporary stroke in the core of the infarct and the time course of TSPO expression with progressive increase from day 4 to 7 post-stroke in rats. This issue of high/low SA should been given some consideration most particularly when using mice as the amount (i.e. in $\mathrm{nmol}$ ) of tracer can more easily reach high level of receptor occupancy in mice due to the small size of the animals as suggested for other tracers[55,56]. One must however note that both sensitivity ( 8-10\% efficiency) and resolution ( $1-1.8 \mathrm{~mm})$ of preclinical PET scanners have dramatically when compared with those reported ( $4 \%$ and $3 \mathrm{~mm}$ ) by Hume et al.[56]. In a similar study, Lartey et al.[57] evaluated the potential of $\left[{ }^{18} \mathrm{~F}\right]$ PBRO6 in mice following $30 \mathrm{~min}$ of intraluminal MCAO and found that $\left[{ }^{18} \mathrm{~F}\right]$ PBR06 could specifically image TSPO in stroke although the amplitude of the difference between ipsi- and contralateral ROI was much smaller than observed in rats with other tracers, including $\left[{ }^{11} \mathrm{C}\right]-(\mathrm{R})-\mathrm{PK} 11195$. This could obviously be due to difference in the sensitivity of the tracer but other factor such as partial volume effect due to the small size of 
1 the mouse brain are probably also having a significant impact on the results. One of the major

2 issue of the studies afore mentioned is that they assess new tracer without comparing them

3 with the reference tracer $\left[{ }^{11} \mathrm{C}\right]-(\mathrm{R})-\mathrm{PK} 11195$ which they are trying to supersede. While many

4 tracer validation studies have done comparisons with [ $\left.{ }^{11} \mathrm{C}\right]-(\mathrm{R})-\mathrm{PK} 11195$ using mostly excite-

5 toxic lesion models (for review see $[20,58]$ ), in more recent studies it appears that direct

6 comparisons (i.e. animals scanned twice, once with $\left[{ }^{11} \mathrm{C}\right]-(\mathrm{R})-\mathrm{PK} 11195$ and once with the

7 tracer to be tested) is essential when using more clinically relevant, but more variable, models

8 such as stroke. For example and as described above, Martin et al.[28] provided evidence that

$9 \quad\left[{ }^{18} \mathrm{~F}\right] D P A-714$ was a suitable tracer for TSPO imaging in stroke (see paragraph above); they did not however provided direct evidence of its superiority vs $\left[{ }^{11} \mathrm{C}\right]-(\mathrm{R})-\mathrm{PK} 11195$. We later showed[53] that $\left[{ }^{18}\right.$ F]DPA-714 provided a better contrast (ipsi- to contralateral ratio) than

$12\left[{ }^{11} \mathrm{C}\right]-(\mathrm{R})-\mathrm{PK} 11195$ only when comparing animals that had been scanned with both tracer sequentially, whereas we were able to obtain a similar results using the less variable model of intrastriatal injection of AMPA and unpaired scans[59]. Taking into account our previous experience[53], we used this more robust study design to later evaluate $\left[{ }^{18} \mathrm{~F}\right] \mathrm{GE}-180[54]$.

Overall, both $\left[{ }^{18} \mathrm{~F}\right] \mathrm{DPA}-714$ and $\left[{ }^{18} \mathrm{~F}\right] \mathrm{GE}-180$ provided better contrast than $\left[{ }^{11} \mathrm{C}\right]-(\mathrm{R})-\mathrm{PK} 11195$, with the most interesting feature being a significantly reduced non-specific (contralateral) uptake when compared to $\left[{ }^{11} \mathrm{C}\right]-(\mathrm{R})-\mathrm{PK} 11195$, supporting both tracers as strong candidate for TSPO imaging. Although not comparing their new tracer, $\left[{ }^{11} \mathrm{C}\right] \mathrm{MBMP}$, in the same animals than $\left[{ }^{11} \mathrm{C}\right]-(\mathrm{R})-\mathrm{PK} 11195$, Tiwari et al.[60] were able to show a significant improvement in ipsito contralateral ratio of $\left[{ }^{11} \mathrm{C}\right] \mathrm{MBMP}$ uptake when compared with $\left[{ }^{11} \mathrm{C}\right]-(\mathrm{R})-\mathrm{PK} 11195$ of similar amplitude (1.5 fold improvement) to those obtained with $\left[{ }^{18} \mathrm{~F}\right] \mathrm{DPA}-714[53]$ and $\left[{ }^{18} \mathrm{~F}\right] \mathrm{GE}-$ $180[54]$ using the same model of stroke. In a more recent publication[61], the same group tested a $\left[{ }^{18} \mathrm{~F}\right]$-labelled derivative of MBMP, $\left[{ }^{18} \mathrm{~F}\right] \mathrm{FEBMP}$, in the same intraluminal stroke model 
1 (30min) but did not perform a direct comparison with $\left[{ }^{11} \mathrm{C}\right]-(\mathrm{R})-\mathrm{PK} 11195$ and only compared

2 their results with their previous study[60]. They found that the BP ${ }_{N D}$ of $\left[{ }^{18} \mathrm{~F}\right] \mathrm{FEBMP}$ was

3 significantly higher than that of $\left[{ }^{11} \mathrm{C}\right] \mathrm{MBMP}$ and $\left[{ }^{11} \mathrm{C}\right]-(\mathrm{R})-\mathrm{PK} 11195$ previously reported[60]

$4 \quad\left(B P_{N D}:\left[{ }^{18} \mathrm{~F}\right]\right.$ FEBMP: $\left.2.72 \pm 0.27,\left[{ }^{11} \mathrm{C}\right] M B M P: 2.03 \pm 0.24,\left[{ }^{11} \mathrm{C}\right]-(\mathrm{R})-\mathrm{PK} 11195: 1.59 \pm 0.33\right)$. More

5 interestingly, and although performed only in 4 subjects by ex vivo autoradiography, they

6 showed that $\left[{ }^{18} \mathrm{~F}\right] \mathrm{FEBMP}$ is as $\left[{ }^{11} \mathrm{C}\right]-(\mathrm{R})-\mathrm{PK} 11195$ insensitive to the TSPO polymorphism in term

7 of binding. This issue of high, mixed and low affinity binders[62-64] has slowed down and

8 complicated dramatically the implementation in clinical settings of new TSPO tracers. The

$9 \quad\left[{ }^{18} \mathrm{~F}\right]$ FEBMP binding data in human subject needs confirmation in a larger study as well as in an in vivo PET study in patients, but if confirmed $\left[{ }^{18} \mathrm{~F}\right] \mathrm{FEBMP}$ may have great potential as TSPO

11 tracer.

\section{TSPO imaging in human subjects}

\section{Material}

Eleven studies have been published from 1992-2014 presenting human TSPO data in 65 patients after ischemic stroke[65-75]. In two separate studies[74,73] there was an overlap in the patient material with two subsequently published articles by the two research groups[72,71]. The mean age \pm SD of patients was $64 \pm 16$ years (range 19-88 years). The studies included 24 females and 35 males. Gender was not reported in one study[68]. The vascular territories involved were the middle cerebral artery (MCA) territory (57 patients), the posterior cerebral artery (PCA) territory (6 patients) $[68,75,72,66]$, and the anterior cerebral artery (ACA) territory (1 patient)[72]. One study reported an ischemic stroke involving the brain stem[68]. Assessments for clinical stroke severity were not consistently reported. In the study by Gerhard et al.[66] neurological signs were rated 1-3 days after stroke in five patients 
1 to the Scandinavian Stroke Scale (SSS) (median 34, mean 32.7, sd 8.4, range 19-36, no

2 impairment is 58/58). Thus, the stroke severity was moderate. In the study by Price et al. [69]

3 neurological signs were rated on admission in four patients to the National Institutes of Health

4 Stroke Scale Score (NIHSS score) (median 12, mean 13, sd 4.3, range 9-19, no impairment

5 0/42). Thus, the stroke severity was minor to moderate. In the studies by Radlinska et al. [70]

6 and Thiel et al. [71] NIHSS test scores (median 2, mean 2.5, SD 1.9, range 0-7) and limb motor

7 function (arm subsection of Rivermead Motor Function Test (RMFT)) (median 13, mean 10.7,

8 sd 4.9, range 1-15, no impairment 15/15) "in the acute post-stroke phase" were reported.

9 Thus, the overall stroke severity was minor but arm function ranging from no impairment to severely impaired. Two studies included a total of six patients with transient ischemic attacks

11 as control subjects[70,71]. The time since debut of symptoms to PET scan is not reported.

12 Two studies included a total of five healthy controls[69,75].

Longitudinal studies were performed in 25 patients: three patients were studied three

14 times and 22 patients were studied two times[65,66,68,69,71,75]. Thus, a total of 93 scans were conducted using positron emission tomography $(P E T, n=85)$ and single photon emission computed tomography (SPECT, $n=8$ ). Patients were scanned from two days to 2 years after

17 stroke. Forty-five patients were scanned with [ $\left.{ }^{11} \mathrm{C}\right]-(\mathrm{R})-\mathrm{PK} 11195[65-71,73], 9$ patients with $\left.{ }^{[11} \mathrm{C}\right]$ vinpocetine[72] (4 of these patients were also examined with PET and $\left[{ }^{11} \mathrm{C}\right]-(\mathrm{R})$ PK11195[73]), 9 patients were scanned with $\left[{ }^{18} \mathrm{~F}\right] \mathrm{DPA}-714[74]$ and 6 patients were scanned with [123I]CLINDE[75]. In three articles the main purpose was to explore the suitability of newly developed second generation tracers for TSPO imaging: [ $\left.{ }^{11} \mathrm{C}\right]$ Vinopocetine[73], 
3 Ramsay et al. [65] the $\left[{ }^{11} \mathrm{C}\right]-(\mathrm{R})-\mathrm{PK} 11195$ outcome parameter was calculated as the tissue

4 radioactivity from $40-60$ min post-injection relative to the integral (0-50 $\mathrm{min}$ ) of radioactivity

5 in metabolite-corrected plasma. In the study by Gerhard et al. [66] the $\left[{ }^{11} \mathrm{C}\right]-(\mathrm{R})-\mathrm{PK} 11195$

6 outcome parameter was calculated as the tissue radioactivity from 30-40 min relative to the

7 corresponding area of the same size on the contralateral, unaffected side of the brain.

8 Radlinska et al. [70] and Thiel et al. [71] used a similar approach but the tissue radioactivity

9 from 20-60 min was preferred. In the [ $\left.{ }^{18} \mathrm{~F}\right] \mathrm{DPA}-714$ paper by Ribeiro et al. [74] both approaches was used with a contralateral hemispheric region and a ipsilateral cerebellar region to define the reference region. In the papers by Gerhard et al. [68] and Price et al. [69] parametric images of regional $\left[{ }^{11} \mathrm{C}\right]-(\mathrm{R})-\mathrm{PK} 11195$ binding was generated using a simplified reference tissue model[76] using the cerebellar hemisphere ipsilateral to the stroke to define the reference region. Pappata et al. [67] used a similar approach but a white matter region in the contralateral hemisphere to define the reference region. In the $\left[{ }^{11} \mathrm{C}\right]$ vinpocetine studies by Gulyás et al. [72] the percentage standardized uptake values \% (\%SUV) was used as main outcome parameter to recognize the difficulties in using cerebellum as a reference region in $\left[{ }^{11} \mathrm{C}\right]-(\mathrm{R})-\mathrm{PK} 11195$ studies. \%SUV is calculated as the radioactivity in the target relative to the total injected radioactivity per body weight $x 100 \%$. In the paper by Feng et al. [75] 2-tissue compartment modeling with metabolite corrected arterial plasma was used. binding potential with and without cerebral blood volume correction were not observed in patients between 2 and 30 days after stroke. Ribeiro et al. [74] described an increased uptake 
1 of $\left[{ }^{18} \mathrm{~F}\right] \mathrm{DPA}-714$ beyond areas of MRI gadolinium enhancement in patients 1-2 weeks after

2 stroke. Modeling of the impact of blood-brain-barrier (BBB) disruption on TSPO binding has

3 been described in a longitudinal study in patients with traumatic brain injury $\left[{ }^{11} \mathrm{C}\right]-(\mathrm{R})-$

4 PK11195-PET scanned 7-10 days, 1 and 6 months after trauma[77]. Analysis using plasma

5 input model showed an increased variability of $K_{1} / k_{2}$ across the brain in patients $7-10$ days

6 after trauma compared to healthy volunteers. This variation was interpreted as representing

7 disruption of the BBB but comparisons to MRI with gadolinium were not done. In studies on

8 TSPO binding in patients with glioblastoma multiforme only a limited overlap between areas

9 of increased TSPO binding and areas with extravasation of gadolinium was demonstrated and

$10 K_{1}$ was not significantly different $[75,78]$. Several studies describe the hematogeous uptake of

11 macrophages (supermagnetic iron oxide particles) as a marker of cellular neuroinflammation

12 to be independent of BBB disruption in patients 1-2 week after stroke[79,80].

The binding affinity of second generation TSPO tracers to TSPO is significantly affected

14 by the rs6971 polymorphism[81,82]. Genotyping was performed in the [ ${ }^{123}$ I]CLINDE study [75]

15 but not done in the $\left[{ }^{18} \mathrm{~F}\right] \mathrm{DPA}-714$ study[74] and the $\left[{ }^{11} \mathrm{C}\right]$ vinpocetine studies $[72,73]$.

Volumes of interest (VOIs) were mostly delineated in the co-registred MR and

17 PET/SPECT images. The ischemic core VOI, assumed to represent not-viable tissue after

18 stroke, was delineated in T1-weighted images. The peri-infarct zone VOI was defined as the

19 high-binding region in the PET/SPECT scan ipsilateral to the stroke minus the overlap with the

20 ischemic core VOI. Remote VOIs was mirrored to the contralateral hemisphere and VOIs were

21 delineated in the brainstem, cerebellum and pyramidal tracts (PT). 
Since binding data are quantified very differently and quantitative regional data not consistently reported it is not possible to lump data together for overall analyses. Several

4 studies have reported regional TSPO changes in the first week after stroke[66,68,72,69,70,65,71]. Very subtle increases in TSPO binding are present already 2-3 days after stroke and located in the periphery of the MR stroke volume $[69,68,70,71]$. Within

7 the first week the volume of increased tracer binding increases substantially and reaches a maximum in the ischemic core zone in the second week[69]. In the peri-infarct zone tracer 9 binding increases in the second week[66,68] and is highest in the third and fourth week $[65,69]$. The absence of longitudinal studies in single subjects that compare tracer binding in the third and fourth week with tracer binding in the second month after stroke impede a more precise determination of peak binding in the peri-infarct zone. The TSPO binding in the peri-infarct zone was clearly present but reduced 150 days after stroke compared to 28 after stroke (figure 2)[68]. In the large study by Thiel et al. [71] uptake ratios in the infarcts was significantly reduced from week 1-3 to 6 months after stroke. Six months after stroke uptake ratios in the infarct were not significantly different from controls (patients with transient ischemic attacks). The range of the uptake ratios six months after stroke appears larger than in controls indicating more variability in patients with possible clinical significance. In the study by Feng et al. [75] TSPO binding normalized in the peri-infarct zone in two patients 187 and 252 days compared to the scans in the fourth week after stroke.

Increases in TSPO binding in areas remote to the immediate surroundings of the infarct have been demonstrated in several studies[67-71,75]. Pappata et al. [67] was the first to describe TSPO binding in thalamus ipsilateral and in some subjects contralateral to the 
1 lesion between 2 and 24 months after stroke. However, interpretations to be made from the

2 study are impeded by the absence of longitudinal studies and/or a control material. Between

3 3-14 days Gerhard et al. [68] did not see remote effects. Gerhard et al. [68] demonstrated the

4 different time-course of changes in TSPO binding in thalamus and pons ipsilateral and

5 contralateral to the lesion. An increased TSPO binding in the thalamus and pons was present

6 ipsilateral to the infarct zone 28 days after stroke and spreading to the contralateral thalamus

7 and pons in the same patient 150 days after stroke (figure 2). These remote changes in TSPO

8 signal are hypothesized to represent Wallerian degeneration along pathways connecting

9 different anatomical areas[68]. Radlinska et al. [70] tested this hypothesis by dividing stroke patients into two groups with $(n=11)$ and without $(n=5)$ subcortical infarcts affecting the pyramidal tract (PT) as verified by MRI. Patients were examined with PET between 2-20 days after stroke. Uptake ratios were not significantly different in the infarct comparing the PT group and the non-PT group. Uptake ratios at the level of pons, midbrain and internal capsule were only increased in the PT group. No changes were detected retrograde to the stroke in the oval center. In the study by Thiel et al. [71] two additional patients were studied compared to the Radlinska et al. [70] study and follow-up data on 16 patients 6 months after the stroke were added (figure 3). The authors reported that significantly increased uptake ratios in remote areas persisted in the PT group at follow-up and correlated with initial PT damage as measured by Diffusion Tensor Imaging (DTI) in the same tract portion. The uptake ratios in the infarct at the first PET-scan correlated with anterograde PT damage at follow-up. The existence of increased TSPO binding in the contralesional cortex has been reported in two studies within the first month following stroke[69] and 287 and 252 days after stroke[75]. A note of caution concerning the use of uptake ratios and reference regions for TSPO 
1 quantification is necessary. It may be a source of bias if TSPO binding is increased in remote

2 areas including contralesional hemisphere and cerebellum.

The studies by Radlinska et al. [70] and Thiel et al. [71] are the only studies reasonably

4 dimensioned to test TSPO binding in relation to clinical outcome. The authors found no

5 significant correlation between RMFT scores (arm function subsection) and infarct size or

6 TSPO uptake in the infarct, pons or midbrain ratio 2-20 days after stroke but a significant

7 negative correlation between RMFT and uptake ratio in the internal capsule[70]. When

8 controlling for damage to PT (fractional anisotropy (FA)) the authors demonstrated a

9 significant positive partial correlation between initial (2-20 days after stroke) remote TSPO

10 binding and RMFT six months after stroke and a trend toward a negative partial correlation

11 between initial TSPO binding in the infarct and RMFT[71]. This indicates that initial TSPO

12 binding in the infarct influence outcome negatively while initial TSPO binding in remote areas

13 influence outcome positively.

\section{Conclusion and future perspectives}

Since 1992 TSPO imaging in stroke has been reported concomitantly in animal models and in human subjects. The most consistent finding across animal models and clinical studies has been the demonstration of temporal changes in TSPO expression in infarcted areas following stroke. TSPO expression is very subtle in the first 2-4 days after stroke and increases for 7-14 days in animals and at least 3-4 weeks in humans. In humans TSPO binding in the peri-infarcted areas is subject to individual variation but appear to normalize in most subjects approximately 6 months after stroke. A differential pattern of localisation of the TSPO expression between permanent and transient ischemia has been noticed in animal models of 
1 whereas the highest TSPO expression are found in the core of the infarct after transient

2 ischemia. From pathophysiological point of view, this observation is in agreement with the

3 different dynamic of events that will take place after permanent vs transient ischemia.

4 Without reperfusion in the core of the infarct following permanent occlusion, the main areas

5 where neuroinflammation will and can take place are the margins and the peri-infarct zones.

6 Whereas in transient ischemia, the reperfusion will drive increased oxidative stress, activation

7 and proliferation of the resident microglia and to some extent, depending on the severity of

8 the stroke, infiltration of macrophages and neutrophils[83,11,28,26]. Increased TSPO binding

9 in areas remote to the immediate surroundings of the infarct appears weeks and months after

10 stroke in patients most consistently reported in relation to the ipsilateral pyramidal tract

11 suggested to reflect Wallerian degeneration but also in contralesional regions in the

12 thalamus, brainstem and cortices. Similarly, in animal TSPO expression is detected in areas

13 remote of the infarct (mostly the ventrolateral part of the thalamus) several months after

14 permanent ischemia, this is thought to be due to retrograde degeneration of thalamo-cortical 15 connections.

What are the functional implications of the spatial and temporal variation in TSPO expression after stroke? Is an increased TSPO expression in the peri-infarct zone or remote areas at a given time point after stroke detrimental or beneficial to stroke recovery? So far only two human studies based upon the same patient material addressed questions of clinical significance and failed to demonstrate robust correlations between TSPO binding in the first weeks after stroke and motor function at baseline and at follow-up after 6 months. Only when controlling for permanent tract damage (based upon DTI studies at follow-up) using partial correlations a significant positive correlation between initial brain stem TSPO binding and 
1 follow-up motor function was demonstrated and a trend toward a negative correlation

2 between initial TSPO binding in the cortical infarction area and motor outcome at 6 months.

4 after stroke is a highly dynamic process with spatial and temporal characteristics that varies

5 between patients. Indeed, more clinical studies addressing the functional implications of

6 TSPO imaging in stroke is warranted. Future TSPO imaging studies are likely to benefit from

7 the new TSPO tracers with higher target to background ratios and should aim at performing

8 quantification of TSPO binding using validated quantitative methods and for second

9 generation TSPO tracers implement information about genotype in the data analysis.

10 Combining TSPO imaging studies in stroke with task-based functional MRI and DTI

11 tractography may provide new insights into the relation between microglial activation and

12 the functional organisation of the residual systems and may facilitate our understanding of how microglia is involved in the change of structure and function after stroke. From a clinical point of view it is of great interest whether TSPO imaging at a given time point after stroke may help in predicting the capacity of an individual for further functional recovery after stroke. Inherent to this approach is testing the effect of drugs targeting neuroinflammatory

17 processes including microglial and astrocytic reaction after stroke and testing the effect of different therapeutic approaches ranging from regional brain stimulation (like repetitive transcranial magnetic stimulation) to conventional physiotherapy. From an experimental point of view, TSPO imaging combined with other modalities such as MRI, multiple PET tracers, DTI allow a better understanding of neuroinflammatory processes occurring poststroke through longitudinal studies in animal, hence increasing the power of the statistical analysis while decreasing the number of animal needed. Only by understanding better the 
1 pathophysiology of stroke and the role of neuroinflammation in stroke, we will be able to

2 design therapeutic strategies aiming at inhibiting the deleterious events of

3 neuroinflammation while supporting repair and remodelling also done by glial cells. From that

4 perspective, it also appears that i) we need to better understand what TSPO functions in glial

5 cells are and what the expression of TSPO means in term of phenotype of glial cells, and that

6 ii) we will also need new biomarkers and tracers to be able to image non-invasively in animal

7 and in patients other events that TSPO imaging does not give us access to. To some extent,

8 progress are being made with imaging of astrogliosis with monoamine oxidase $B$ (MAO-B)

9 tracer $\left[{ }^{11} \mathrm{C}\right]$-deuterium-L-deprenyl[84,85] and cannabinoid type 2 (CB2) receptors[86],

10 although results with the CB2 receptors post-stroke have been disappointing[87]. Several

11 molecules (cytokines and chemokines receptors, adhesion molecules expressed at

12 endothelial level, receptor specific to the immune response or activation of glial cells such as P2X7 receptor, toll-like receptors, etc.) are all potential candidates, but whether developing

14 tracers for them is doable or whether they will prove difficult remains to be determine and is 15 certainly a work under progress.

\section{Compliance with Ethics Guidelines}

Hervé Boutin and Lars H. Pinborg declare no conflicts of interest. The article contains data from studies with human and animal subjects performed by the authors of this article. All procedures followed were in accordance with the ethical standards of the responsible committee on human experimentation (institutional and national) and with the Helsinki Declaration of 1975 , as revised in 2008. Informed consent was obtained from all patients for

22 being included in the study. All institutional and national guidelines for the care and use of 23 laboratory animals were followed. 


\section{Acknowledgements}

2

This work was financially supported by the European Union's Seventh Framework

3 Programme (FP7/2007-2013) under grant agreement HEALTH-F2-2011-278850 (INMiND), the

4 Danish Council for Independent Research, the Research Committee of Rigshospitalet. 


\section{Figure legends:}

2 Figure 1: schematic representation of the time-course of TSPO expression by activated

3 microglia/infiltrated macrophages and astrocytes after transient (A) and permanent brain

4 ischemia (B) (adapted from [25,32,27](A) and [45,47](B), highlighting the slightly earlier and

5 shorter expression pattern following permanent ischemia when compared with transient

6 ischemia. It must be noted that in transient ischemia the highest values of TSPO expression

7 are found in the core of the infarct whereas they are found in the peri-infarcted area after

8 permanent ischemia. Values were estimated from the data available in each publications

9 either in the text or graphs, normalised to the peak value, and averaged across all studies.

10 Mean $\pm 1 S D$ values illustrate the variability at each time-point across studies.

12 Figure 2: [11C](R)-PK11195 PET and MRI scans for a patient at different time points: (a-h) show transverse $(a-d)$ and coronal $(e-h)$ MRI and PET sections through the brain of a patient who was scanned 28 and 150 days after the ischemic stroke. (a) and (e) show the T1weighted MRI after 28 days and (b) and (f) the [11C](R)-PK11195 BP map co-registered to the MRI. In (c) and (g), the same transverse and coronal planes with the [11C](R)-PK11195 BP map co- registered to the MRI are shown after 150 days. At 28 days, the $[11 C](R)-$ PK11195 PET and T1-weighted MRI hypointensity cover a similar area while after 150 days the PET lesion has expanded to the ipsi- and contralateral thalamus. (d) and (h) demonstrate the evolving atrophy in this patient 150 days after the ischemic stroke as seen by MR subtraction imaging. The image colors are calibrated for BP values from 0 (dark blue) to one

22 (red); values N1 appear white. Extracerebral binding has been masked. Reprinted from

23 Gerhard et al. [68] with permission from Elsevier. 
2 Figure 3: (A) Microglial activation in a patient with small subcortical infarct and good

3 recovery. Initial activated microglia in infarct decreased over 6 months (white arrows),

4 whereas microglial activation in brain stem persisted (red arrows). DTI showed decreased FA

5 primarily in infarct (blue arrows) and less along tract at level of cerebral peduncles (yellow

6 arrows). (B) Patient with complete transection of PT and poor recovery. Microglial activity in

7 infarct decreased but still persisted after 6 mo (white arrows), as did activity in brain stem

8 (red arrows). FA decreased in area of infarct (blue arrows) and along tract in cerebral

9 peduncle (yellow arrows). Microglial activity in patient in whom PT was not affected (C)

10 decreased over 6 mo (white arrows). No tracer uptake at level of brain stem was observed,

11 and FA along tracts was not decreased. This research was originally published in JNM by

12 Thiel et al.[71]. Copyrights by the Society of Nuclear Medicine and Molecular Imaging, Inc.

\section{Author contribution}

14 Hervé Boutin: Literature search and review, manuscript writing and editing.

15 Lars H. Pinborg: Literature search and review, manuscript writing and editing. 
1. Braestrup C, Squires RF (1977) Specific benzodiazepine receptors in rat brain characterized by high-affinity $(3 \mathrm{H})$ diazepam binding. Proceedings of the National Academy of Sciences of the United States of America 74 (9):3805-3809

2. Le Fur G, Vaucher N, Perrier ML, Flamier A, Benavides J, Renault C, Dubroeucq MC, Gueremy C, Uzan A (1983) Differentiation between two ligands for peripheral benzodiazepine binding sites, [3H]RO5-4864 and [3H]PK 11195, by thermodynamic studies. Life Sci 33:449-457

3. Papadopoulos V, Baraldi M, Guilarte TR, Knudsen TB, Lacapere JJ, Lindemann P, Norenberg MD, Nutt D, Weizman A, Zhang MR, Gavish M (2006) Translocator protein (18kDa): new nomenclature for the peripheral-type benzodiazepine receptor based on its structure and molecular function. Trends in pharmacological sciences 27 (8):402-409. doi:10.1016/j.tips.2006.06.005

4. Dubois A, Benavides J, Peny B, Duverger D, Fage D, Gotti B, MacKenzie ET, Scatton B (1988) Imaging of primary and remote ischaemic and excitotoxic brain lesions. An autoradiographic study of peripheral type benzodiazepine binding sites in the rat and cat. Brain research 445 (1):77-90

5. Benavides J, Capdeville C, Dauphin F, Dubois A, Duverger D, Fage D, Gotti B, MacKenzie ET, Scatton B (1990) The quantification of brain lesions with an $w_{3}$ site ligand: a critical analysis of animal models of cerebral ischaemia and neurodegeneration. Brain research 522:275-289 6. Petit-Taboue MC, Baron JC, Barre L, Travere JM, Speckel D, Camsonne R, MacKenzie ET (1991) Brain kinetics and specific binding of [11C]PK 11195 to omega 3 sites in baboons: positron emission tomography study. Eur J Pharmacol 200:347-351

7. Myers R, Manjil LG, Cullen BM, Price GW, Frackowiak RS, Cremer JE (1991) Macrophage and astrocyte populations in relation to [3H]PK 11195 binding in rat cerebral cortex following a local ischaemic lesion. J Cereb Blood Flow Metab 11:314-322

8. Stephenson DT, Schober DA, Smalstig EB, Mincy RE, Gehlert DR, Clemens JA (1995) Peripheral benzodiazepine receptors are colocalized with activated microglia following transient global forebrain ischemia in the rat. J Neurosci 15:5263-5274

9. Cremer JE, Hume SP, Cullen BM, Myers R, Manjil LG, Turton DR, Luthra SK, Bateman DM, Pike VW (1992) The distribution of radioactivity in brains of rats given [N-methyl-11C]PK 11195 in vivo after induction of a cortical ischaemic lesion. Int J Rad Appl Instrum B 19:159166

10. Shah F, Hume SP, Pike VW, Ashworth S, McDermott J (1994) Synthesis of the enantiomers of [N-methyl-11C]PK 11195 and comparison of their behaviours as radioligands for PK binding sites in rats. Nucl Med Biol 21:573-581

11. Stoll G, Jander S, Schroeter M (1998) Inflammation and glial responses in ischemic brain lesions. Prog Neurobiol 56:149-171

12. Touzani O, Boutin H, Chuquet J, Rothwell N (1999) Potential mechanisms of interleukin-1 involvement in cerebral ischaemia. J Neuroimmunol 100:203-215

13. Sette G, Baron JC, Young AR, Miyazawa H, Tillet I, Barré L, Travère JM, Derlon JM, MacKenzie ET (1993) In vivo mapping of brain benzodiazepine receptor changes by positron emission tomography after focal ischemia in the anesthetized baboon. Stroke; a journal of cerebral circulation 24:2046-2057 VW, Innis RB, Fujita M (2007) PET imaging with [(11)C]PBR28 can localize and quantify 
upregulated peripheral benzodiazepine receptors associated with cerebral ischemia in rat. Neurosci Lett 411:200-205

15. Kenny BA, MacKinnon AC, Spedding M, Brown CM (1993) Changes in [3H]-PK 11195 and [3H]-8-OH-DPAT binding following forebrain ischaemia in the gerbil. British journal of pharmacology 109 (2):437-442

16. Earley B, Canney M, Clune B, Caldwell M, Leonard BE, Junien JL (1996) The effects of MK801, ifenprodil, JO 1784, JO 1994 and JO 1997 on PK 11195 receptor binding, nitric oxide synthase (NO synthase) activity and infarct volume in a mouse model of focal cerebral ischaemia. Neurochemistry international 28 (5-6):509-521

17. Craven JA, Conway EL (1997) Effects of alpha 2-adrenoceptor antagonists and imidazoline2-receptor ligands on neuronal damage in global ischaemia in the rat. Clin Exp Pharmacol Physiol 24 (2):204-207

18. Conway EL, Gundlach AL, Craven JA (1998) Temporal changes in glial fibrillary acidic protein messenger RNA and [3H]PK11195 binding in relation to imidazoline-I2-receptor and alpha 2-adrenoceptor binding in the hippocampus following transient global forebrain ischaemia in the rat. Neuroscience 82 (3):805-817

19. Miyazawa N, Saji H, Takaishi Y, Nukui H (2000) Protective effect of FK506 in the reperfusion model after short-term occlusion of middle cerebral artery in the rat: assessment by autoradiography using [125I]PK-11195. Neurological research 22 (6):630-633

20. Chauveau F, Boutin H, Van Camp N, Dolle F, Tavitian B (2008) Nuclear imaging of neuroinflammation: a comprehensive review of [11C]PK11195 challengers. Eur J Nucl Med Mol Imaging 35 (12):2304-2319. doi:10.1007/s00259-008-0908-9

21. Bacigaluppi M, Comi G, Hermann DM (2010) Animal models of ischemic stroke. Part two: modeling cerebral ischemia. Open Neurol J 4:34-38. doi:10.2174/1874205X01004020034 22. Bacigaluppi M, Comi G, Hermann DM (2010) Animal models of ischemic stroke. Part one: modeling risk factors. Open Neurol J 4:26-33. doi:10.2174/1874205X01004020026

23. Durukan A, Tatlisumak T (2009) Animal models of ischemic stroke. Handbook of clinical neurology / edited by PJ Vinken and GW Bruyn 92:43-66. doi:10.1016/S0072-9752(08)019039

24. Fluri F, Schuhmann MK, Kleinschnitz C (2015) Animal models of ischemic stroke and their application in clinical research. Drug Des Devel Ther 9:3445-3454. doi:10.2147/DDDT.S56071 25. Rojas S, Martin A, Arranz MJ, Pareto D, Purroy J, Verdaguer E, Llop J, Gomez V, Gispert JD, Millan O, Chamorro A, Planas AM (2007) Imaging brain inflammation with [(11)C]PK11195 by PET and induction of the peripheral-type benzodiazepine receptor after transient focal ischemia in rats. J Cereb Blood Flow Metab 27:1975-1986

26. Martin A, Boisgard R, Kassiou M, Dolle F, Tavitian B (2010) Reduced PBR/TSPO Expression After Minocycline Treatment in a Rat Model of Focal Cerebral Ischemia: A PET Study Using [(18)F]DPA-714. Mol Imaging Biol

27. Martin A, Boisgard R, Theze B, Van CN, Kuhnast B, Damont A, Kassiou M, Dolle F, Tavitian $B$ (2010) Evaluation of the PBR/TSPO radioligand [(18)F]DPA-714 in a rat model of focal cerebral ischemia. J Cereb Blood Flow Metab 30:230-241

28. Martin A, Boisgard R, Theze B, Van Camp N, Kuhnast B, Damont A, Kassiou M, Dolle F, Tavitian B (2010) Evaluation of the PBR/TSPO radioligand [(18)F]DPA-714 in a rat model of focal cerebral ischemia. J Cereb Blood Flow Metab 30 (1):230-241. doi:10.1038/jcbfm.2009.205

29. Hughes JL, Jones PS, Beech JS, Wang D, Menon DK, Aigbirhio FI, Fryer TD, Baron JC (2012) A microPET study of the regional distribution of [11C]-PK11195 binding following temporary 
focal cerebral ischemia in the rat. Correlation with post mortem mapping of microglia activation. Neuroimage 59 (3):2007-2016. doi:10.1016/j.neuroimage.2011.10.060

30. Lavisse S, Guillermier M, Herard AS, Petit F, Delahaye M, Van CN, Ben HL, Lebon V, Remy P, Dolle F, Delzescaux T, Bonvento G, Hantraye P, Escartin C (2012) Reactive astrocytes overexpress TSPO and are detected by TSPO positron emission tomography imaging. J Neurosci 32:10809-10818

31. Arnberg F, Lundberg J, Soderman M, Damberg P, Holmin S (2012) Image-guided method in the rat for inducing cortical or striatal infarction and for controlling cerebral blood flow under MRI. Stroke; a journal of cerebral circulation 43 (9):2437-2443. doi:10.1161/STROKEAHA.112.655126

32. Toth M, Little P, Arnberg F, Haggkvist J, Mulder J, Halldin C, Gulyas B, Holmin S (2015) Acute neuroinflammation in a clinically relevant focal cortical ischemic stroke model in rat: longitudinal positron emission tomography and immunofluorescent tracking. Brain Struct Funct. doi:10.1007/s00429-014-0970-y

33. Rueger MA, Muesken S, Walberer M, Jantzen SU, Schnakenburg K, Backes H, Graf R, Neumaier B, Hoehn M, Fink GR, Schroeter M (2012) Effects of minocycline on endogenous neural stem cells after experimental stroke. Neuroscience 215:174-183. doi:10.1016/j.neuroscience.2012.04.036

34. Banwell V, Sena ES, Macleod MR (2009) Systematic review and stratified meta-analysis of the efficacy of interleukin-1 receptor antagonist in animal models of stroke. J Stroke Cerebrovasc Dis 18:269-276

35. Parry-Jones A, Boutin H, Denes A, McColl B, Hopkins S, Allan S, Tyrrell P (2010) Interleukin1 receptor antagonist in animal models of stroke: a fair summing up? J Stroke Cerebrovasc Dis 19:512-513

36. Pinteaux E, Rothwell NJ, Boutin H (2006) Neuroprotective actions of endogenous interleukin-1 receptor antagonist (IL-1ra) are mediated by glia. Glia 53:551-556

37. Pradillo JM, Denes A, Greenhalgh AD, Boutin H, Drake C, McColl BW, Barton E, Proctor SD, Russell JC, Rothwell NJ, Allan SM (2012) Delayed administration of interleukin-1 receptor antagonist reduces ischemic brain damage and inflammation in comorbid rats. J Cereb Blood Flow Metab 32:1810-1819

38. Ali C, Nicole O, Docagne F, Lesne S, MacKenzie ET, Nouvelot A, Buisson A, Vivien D (2000) Ischemia-induced interleukin- 6 as a potential endogenous neuroprotective cytokine against NMDA receptor-mediated excitotoxicity in the brain. J Cereb Blood Flow Metab 20:956-966 39. Ali C, Nicole O, Docagne F, Lesne S, Nouvelot A, MacKenzie ET, Buisson A, Vivien D (1999) Evidence that IL- 6 is selectively neuroprotective against excitotoxic-type of ischemic neuronal death. Paper presented at the J. Cereb. Blood Flow Metab, 1999

40. Hill JK, Gunion-Rinker L, Kulhanek D, Lessov N, Kim S, Clark WM, Dixon MP, Nishi R, StenzelPoore MP, Eckenstein FP (1999) Temporal modulation of cytokine expression following focal cerebral ischemia in mice. Brain research 820:45-54

41. Dodel R, Spottke A, Gerhard A, Reuss A, Reinecker S, Schimke N, Trenkwalder C, SixelDoring F, Herting B, Kamm C, Gasser T, Sawires M, Geser F, Kollensperger M, Seppi K, Kloss M, Krause M, Daniels C, Deuschl G, Bottger S, Naumann M, Lipp A, Gruber D, Kupsch A, Du Y, Turkheimer F, Brooks DJ, Klockgether T, Poewe W, Wenning G, Schade-Brittinger C, Oertel WH, Eggert K (2010) Minocycline 1-year therapy in multiple-system-atrophy: effect on clinical symptoms and [(11)C] (R)-PK11195 PET (MEMSA-trial). Movement disorders : official journal of the Movement Disorder Society 25:97-107 
42. Wang Y, Yue X, Kiesewetter DO, Wang Z, Lu J, Niu G, Teng G, Chen X (2014) [(18)F]DPA714 PET Imaging of AMD3100 Treatment in a Mouse Model of Stroke. Molecular pharmaceutics 11:3463-3470

43. Boutin H, Prenant C, Galea J, Greenhalgh A, Julyan P, Brown G, Herholz K, Kassiou M, Rothwell NJ (2008) [ $\left.{ }^{18} \mathrm{~F}\right] \mathrm{DPA}-714$ : evaluation and direct comparison with [ $\left.{ }^{11} \mathrm{C}\right] \mathrm{PK} 11195$ in a model of cerebral ischemia in rats. Paper presented at the 1st World Molecular Imaging Congress, $11 / 10 / 2008$

44. Schroeter M, Dennin MA, Walberer M, Backes H, Neumaier B, Fink GR, Graf R (2009) Neuroinflammation extends brain tissue at risk to vital peri-infarct tissue: a double tracer [11C]PK11195- and [18F]FDG-PET study. J Cereb Blood Flow Metab 29:1216-1225

45. Fukumoto D, Hosoya T, Nishiyama S, Harada N, Iwata H, Yamamoto S, Tsukada H (2011) Multiparametric assessment of acute and subacute ischemic neuronal damage: a small animal positron emission tomography study with rat photochemically induced thrombosis model. Synapse 65:207-214

46. Fukumoto D, Nishiyama S, Harada N, Yamamoto S, Tsukada H (2012) Detection of ischemic neuronal damage with [(1)(8)F]BMS-747158-02, a mitochondrial complex-1 positron emission tomography ligand: small animal PET study in rat brain. Synapse 66:909-917

47. Walberer $M$, Jantzen SU, Backes $H$, Rueger MA, Keuters MH, Neumaier B, Hoehn M, Fink GR, Graf R, Schroeter M (2014) In-vivo detection of inflammation and neurodegeneration in the chronic phase after permanent embolic stroke in rats. Brain research 1581:80-88. doi:10.1016/j.brainres.2014.05.030

48. Fujie W, Kirino T, Tomukai N, Iwasawa T, Tamura A (1990) Progressive shrinkage of the thalamus following middle cerebral artery occlusion in rats. Stroke; a journal of cerebral circulation 21:1485-1488

49. lizuka H, Sakatani K, Young W (1990) Neural damage in the rat thalamus after cortical infarcts. Stroke; a journal of cerebral circulation 21:790-794

50. Yui J, Maeda J, Kumata K, Kawamura K, Yanamoto K, Hatori A, Yamasaki T, Nengaki N, Higuchi M, Zhang MR (2010) 18F-FEAC and 18F-FEDAC: PET of the monkey brain and imaging of translocator protein (18 kDa) in the infarcted rat brain. J Nucl Med 51:1301-1309

51. Yui J, Hatori A, Kawamura K, Yanamoto K, Yamasaki T, Ogawa M, Yoshida Y, Kumata K, Fujinaga M, Nengaki N, Fukumura T, Suzuki K, Zhang MR (2011) Visualization of early infarction in rat brain after ischemia using a translocator protein (18 kDa) PET ligand [11C]DAC with ultra-high specific activity. Neuroimage 54:123-130

52. Yui J, Hatori A, Yanamoto K, Takei M, Nengaki N, Kumata K, Kawamura K, Yamasaki T, Suzuki K, Zhang MR (2010) Imaging of the translocator protein (18 kDa) in rat brain after ischemia using [11C]DAC with ultra-high specific activity. Synapse 64 (6):488-493. doi:10.1002/syn.20761

53. Boutin H, Prenant C, Maroy R, Galea J, Greenhalgh AD, Smigova A, Cawthorne C, Julyan $P$, Wilkinson SM, Banister SD, Brown G, Herholz K, Kassiou M, Rothwell NJ (2013) [18F]DPA-714: direct comparison with [11C]PK11195 in a model of cerebral ischemia in rats. PloS one 8 (2):e56441. doi:10.1371/journal.pone.0056441

54. Boutin H, Murray K, Pradillo J, Maroy R, Smigova A, Gerhard A, Jones PA, Trigg W (2015) 18F-GE-180: a novel TSPO radiotracer compared to 11C-R-PK11195 in a preclinical model of stroke. Eur J Nucl Med Mol Imaging 42 (3):503-511. doi:10.1007/s00259-014-2939-8 55. Higuchi M (2009) Visualization of brain amyloid and microglial activation in mouse models of Alzheimer's disease. Curr Alzheimer Res 6:137-143 
56. Hume SP, Gunn RN, Jones T (1998) Pharmacological constraints associated with positron emission tomographic scanning of small laboratory animals. Eur J Nucl Med 25 (2):173-176 57. Lartey FM, Ahn GO, Shen B, Cord KT, Smith T, Chua JY, Rosenblum S, Liu H, James ML, Chernikova S, Lee SW, Pisani LJ, Tirouvanziam R, Chen JW, Palmer TD, Chin FT, Guzman R, Graves EE, Loo BW, Jr. (2014) PET imaging of stroke-induced neuroinflammation in mice using [18F]PBR06. Mol Imaging Biol 16 (1):109-117. doi:10.1007/s11307-013-0664-5

58. Dolle F, Luus C, Reynolds A, Kassiou M (2009) Radiolabelled molecules for imaging the translocator protein (18 kDa) using positron emission tomography. Current medicinal chemistry 16 (22):2899-2923

59. Chauveau F, Van Camp N, Dolle F, Kuhnast B, Hinnen F, Damont A, Boutin H, James M, Kassiou M, Tavitian $B$ (2009) Comparative evaluation of the translocator protein radioligands 11C-DPA-713, 18F-DPA-714, and 11C-PK11195 in a rat model of acute neuroinflammation. J Nucl Med 50 (3):468-476. doi:10.2967/jnumed.108.058669

60. Tiwari AK, Ji B, Yui J, Fujinaga M, Yamasaki T, Xie L, Luo R, Shimoda Y, Kumata K, Zhang Y, Hatori A, Maeda J, Higuchi M, Wang F, Zhang MR (2015) [(18)F]FEBMP: Positron Emission Tomography Imaging of TSPO in a Model of Neuroinflammation in Rats, and in vitro Autoradiograms of the Human Brain. Theranostics 5 (9):961-969. doi:10.7150/thno.12027 61. Tiwari AK, Yui J, Fujinaga M, Kumata K, Shimoda Y, Yamasaki T, Xie L, Hatori A, Maeda J, Nengaki N, Zhang MR (2014) Characterization of a novel acetamidobenzoxazolone-based PET ligand for translocator protein $(18 \mathrm{kDa})$ imaging of neuroinflammation in the brain. Journal of neurochemistry 129:712-720

62. Owen DR, Howell OW, Tang SP, Wells LA, Bennacef I, Bergstrom M, Gunn RN, Rabiner EA, Wilkins MR, Reynolds R, Matthews PM, Parker CA (2010) Two binding sites for [3H]PBR28 in human brain: implications for TSPO PET imaging of neuroinflammation. J Cereb Blood Flow Metab 30 (9):1608-1618. doi:10.1038/jcbfm.2010.63

63. Owen DR, Gunn RN, Rabiner EA, Bennacef I, Fujita M, Kreisl WC, Innis RB, Pike VW, Reynolds R, Matthews PM, Parker CA (2011) Mixed-affinity binding in humans with 18-kDa translocator protein ligands. J Nucl Med 52 (1):24-32. doi:10.2967/jnumed.110.079459

64. Guo Q, Owen DR, Rabiner EA, Turkheimer FE, Gunn RN (2012) Identifying improved TSPO PET imaging probes through biomathematics: the impact of multiple TSPO binding sites in vivo. Neuroimage 60 (2):902-910. doi:10.1016/j.neuroimage.2011.12.078

65. Ramsay SC, Weiller C, Myers R, Cremer JE, Luthra SK, Lammertsma AA, Frackowiak RS (1992) Monitoring by PET of macrophage accumulation in brain after ischaemic stroke. Lancet 339 (8800):1054-1055

66. Gerhard A, Neumaier B, Elitok E, Glatting G, Ries V, Tomczak R, Ludolph AC, Reske SN (2000) In vivo imaging of activated microglia using [11C]PK11195 and positron emission tomography in patients after ischemic stroke. Neuroreport 11 (13):2957-2960

67. Pappata S, Levasseur M, Gunn RN, Myers R, Crouzel C, Syrota A, Jones T, Kreutzberg GW, Banati RB (2000) Thalamic microglial activation in ischemic stroke detected in vivo by PET and [11C]PK1195. Neurology 55 (7):1052-1054

68. Gerhard A, Schwarz J, Myers R, Wise R, Banati RB (2005) Evolution of microglial activation in patients after ischemic stroke: a [11C](R)-PK11195 PET study. Neuroimage 24 (2):591-595. doi:10.1016/j.neuroimage.2004.09.034

69. Price CJ, Wang D, Menon DK, Guadagno JV, Cleij M, Fryer T, Aigbirhio F, Baron JC, Warburton EA (2006) Intrinsic activated microglia map to the peri-infarct zone in the subacute phase of ischemic stroke. Stroke; a journal of cerebral circulation 37 (7):1749-1753. doi:10.1161/01.STR.0000226980.95389.0b 
70. Radlinska BA, Ghinani SA, Lyon P, Jolly D, Soucy JP, Minuk J, Schirrmacher R, Thiel A (2009) Multimodal microglia imaging of fiber tracts in acute subcortical stroke. Annals of neurology 66 (6):825-832. doi:10.1002/ana.21796

71. Thiel A, Radlinska BA, Paquette C, Sidel M, Soucy JP, Schirrmacher R, Minuk J (2010) The temporal dynamics of poststroke neuroinflammation: a longitudinal diffusion tensor imagingguided PET study with 11C-PK11195 in acute subcortical stroke. J Nucl Med 51 (9):1404-1412. doi:10.2967/jnumed.110.076612

72. Gulyas B, Toth M, Schain M, Airaksinen A, Vas A, Kostulas K, Lindstrom P, Hillert J, Halldin $C$ (2012) Evolution of microglial activation in ischaemic core and peri-infarct regions after stroke: a PET study with the TSPO molecular imaging biomarker $[((11)) \mathrm{C}]$ vinpocetine. Journal of the neurological sciences 320 (1-2):110-117. doi:10.1016/j.jns.2012.06.026

73. Gulyas B, Toth M, Vas A, Shchukin E, Kostulas K, Hillert J, Halldin C (2012) Visualising neuroinflammation in post-stroke patients: a comparative PET study with the TSPO molecular imaging biomarkers [11C]PK11195 and [11C]vinpocetine. Current radiopharmaceuticals 5 (1):19-28

74. Ribeiro MJ, Vercouillie J, Debiais S, Cottier JP, Bonnaud I, Camus V, Banister S, Kassiou M, Arlicot N, Guilloteau D (2014) Could (18) F-DPA-714 PET imaging be interesting to use in the early post-stroke period? EJNMMI research 4:28. doi:10.1186/s13550-014-0028-4

75. Feng L, Svarer C, Thomsen G, de Nijs R, Larsen VA, Jensen P, Adamsen D, Dyssegaard A, Fischer W, Meden P, Krieger D, Moller K, Knudsen GM, Pinborg LH (2014) In vivo quantification of cerebral translocator protein binding in humans using 6-chloro-2-(4'-123Iiodophenyl)-3-(N,N-diethyl)-imidazo[1,2-a]pyridine-3-acetamid e SPECT. J Nucl Med 55 (12):1966-1972. doi:10.2967/jnumed.114.143727

76. Gunn RN, Lammertsma AA, Hume SP, Cunningham VJ (1997) Parametric imaging of ligandreceptor binding in PET using a simplified reference region model. Neuroimage 6 (4):279-287. doi:10.1006/nimg.1997.0303

77. Folkersma $H$, Boellaard R, Vandertop WP, Kloet RW, Lubberink $M$, Lammertsma AA, van Berckel BN (2009) Reference tissue models and blood-brain barrier disruption: lessons from (R)-[11C]PK11195 in traumatic brain injury. J Nucl Med 50 (12):1975-1979. doi:10.2967/jnumed.109.067512

78. Jensen P, Feng L, Law I, Svarer C, Knudsen GM, Mikkelsen JD, de Nijs R, Larsen VA, Dyssegaard A, Thomsen G, Fischer W, Guilloteau D, Pinborg LH (2015) TSPO Imaging in Glioblastoma Multiforme: A Direct Comparison Between 123I-CLINDE SPECT, 18F-FET PET, and Gadolinium-Enhanced MR Imaging. J Nucl Med 56 (9):1386-1390. doi:10.2967/jnumed.115.158998

79. Saleh A, Schroeter M, Jonkmanns C, Hartung HP, Modder U, Jander S (2004) In vivo MRI of brain inflammation in human ischaemic stroke. Brain : a journal of neurology 127 (Pt 7):1670-1677. doi:10.1093/brain/awh191

80. Nighoghossian N, Wiart M, Cakmak S, Berthezene Y, Derex L, Cho TH, Nemoz C, Chapuis F, Tisserand GL, Pialat JB, Trouillas P, Froment JC, Hermier M (2007) Inflammatory response after ischemic stroke: a USPIO-enhanced MRI study in patients. Stroke; a journal of cerebral circulation 38 (2):303-307. doi:10.1161/01.STR.0000254548.30258.f2

81. Owen DR, Yeo AJ, Gunn RN, Song K, Wadsworth G, Lewis A, Rhodes C, Pulford DJ, Bennacef I, Parker CA, StJean PL, Cardon LR, Mooser VE, Matthews PM, Rabiner EA, Rubio JP (2012) An 18-kDa translocator protein (TSPO) polymorphism explains differences in binding affinity of the PET radioligand PBR28. J Cereb Blood Flow Metab 32 (1):1-5. doi:10.1038/jcbfm.2011.147 
1 82. KreisI WC, Jenko KJ, Hines CS, Lyoo CH, Corona W, Morse CL, Zoghbi SS, Hyde T, Kleinman

2 JE, Pike VW, McMahon FJ, Innis RB (2013) A genetic polymorphism for translocator protein

$318 \mathrm{kDa}$ affects both in vitro and in vivo radioligand binding in human brain to this putative

4 biomarker of neuroinflammation. J Cereb Blood Flow Metab 33 (1):53-58.

5 doi:10.1038/jcbfm.2012.131

6 83. Denes A, Vidyasagar R, Feng J, Narvainen J, McColl BW, Kauppinen RA, Allan SM (2007)

7 Proliferating resident microglia after focal cerebral ischaemia in mice. J Cereb Blood Flow

8 Metab 27 (12):1941-1953. doi:10.1038/sj.jcbfm.9600495

9 84. Rodriguez-Vieitez E, Ni R, Gulyas B, Toth M, Haggkvist J, Halldin C, Voytenko L, Marutle A, 10 Nordberg A (2015) Astrocytosis precedes amyloid plaque deposition in Alzheimer APPswe 11 transgenic mouse brain: a correlative positron emission tomography and in vitro imaging 12 study. Eur J Nucl Med Mol Imaging

13 85. Carter SF, Scholl M, Almkvist O, Wall A, Engler H, Langstrom B, Nordberg A (2012) Evidence 14 for astrocytosis in prodromal Alzheimer disease provided by 11C-deuterium-L-deprenyl: a 15 multitracer PET paradigm combining 11C-Pittsburgh compound B and 18F-FDG. J Nucl Med $16 \quad 53: 37-46$

17 86. Evens N, Vandeputte C, Coolen C, Janssen P, Sciot R, Baekelandt V, Verbruggen AM, 18 Debyser Z, Van Laere K, Bormans GM (2012) Preclinical evaluation of [11C]NE40, a type 2 19 cannabinoid receptor PET tracer. Nuclear medicine and biology 39 (3):389-399. 20 doi:10.1016/j.nucmedbio.2011.09.005

21 87. Vandeputte C, Casteels C, Struys T, Koole M, van VD, Evens N, Gerits A, Dresselaers T, 22 Lambrichts I, Himmelreich U, Bormans G, Van LK (2012) Small-animal PET imaging of the type 231 and type 2 cannabinoid receptors in a photothrombotic stroke model. Eur J Nucl Med Mol 24 Imaging 39:1796-1806 

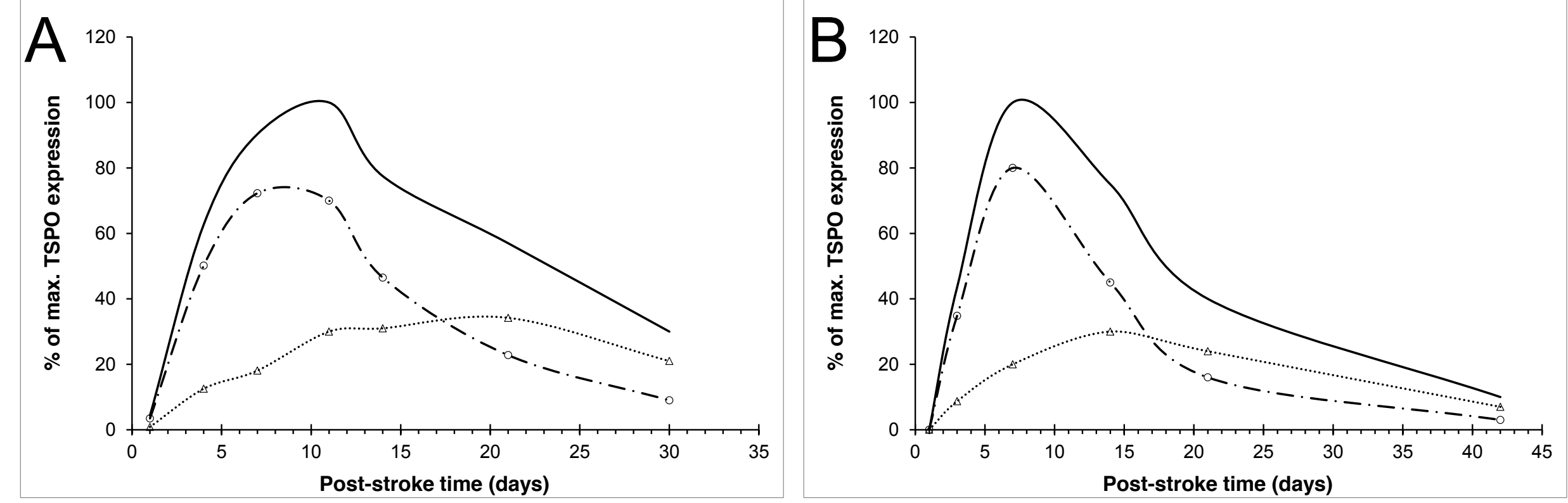

—TSPO expression

$\rightarrow \cdot$ microglial activation/macrophages infiltration

..... astrogliosis 


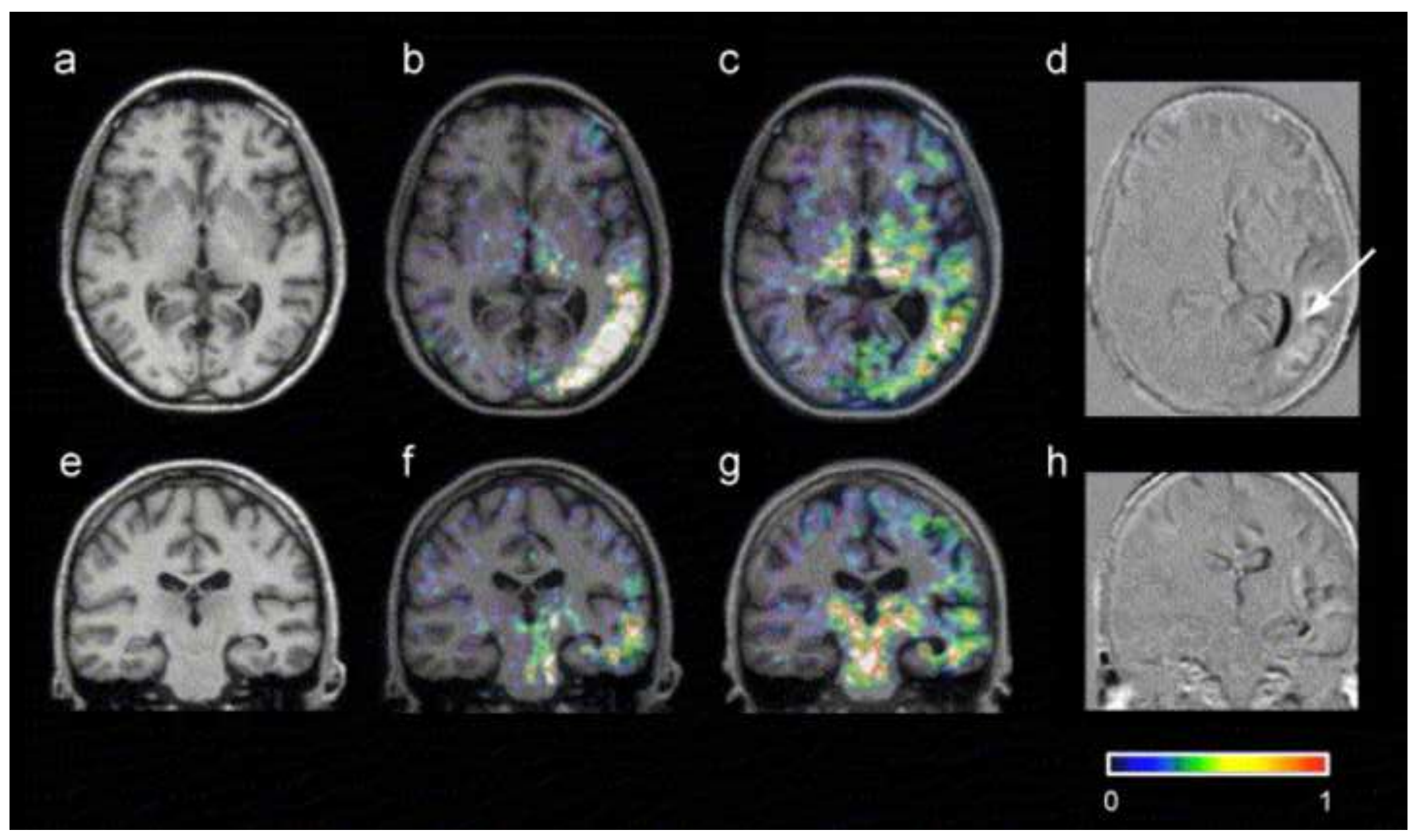




\section{Figure 3}

Click here to download Figure: Figure3_JNM.jpg

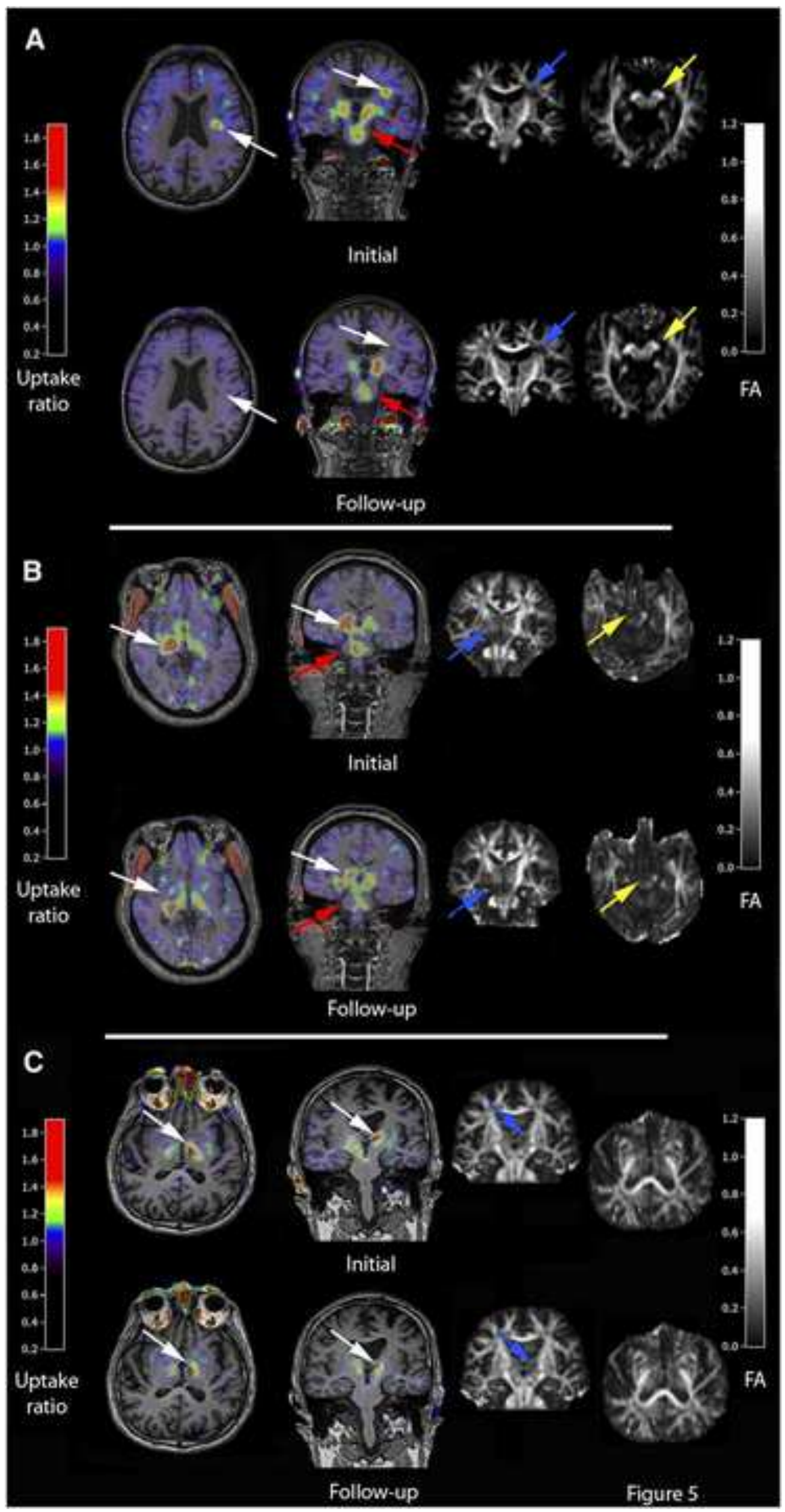

